Provided for non-commercial research and education use. Not for reproduction, distribution or commercial use.

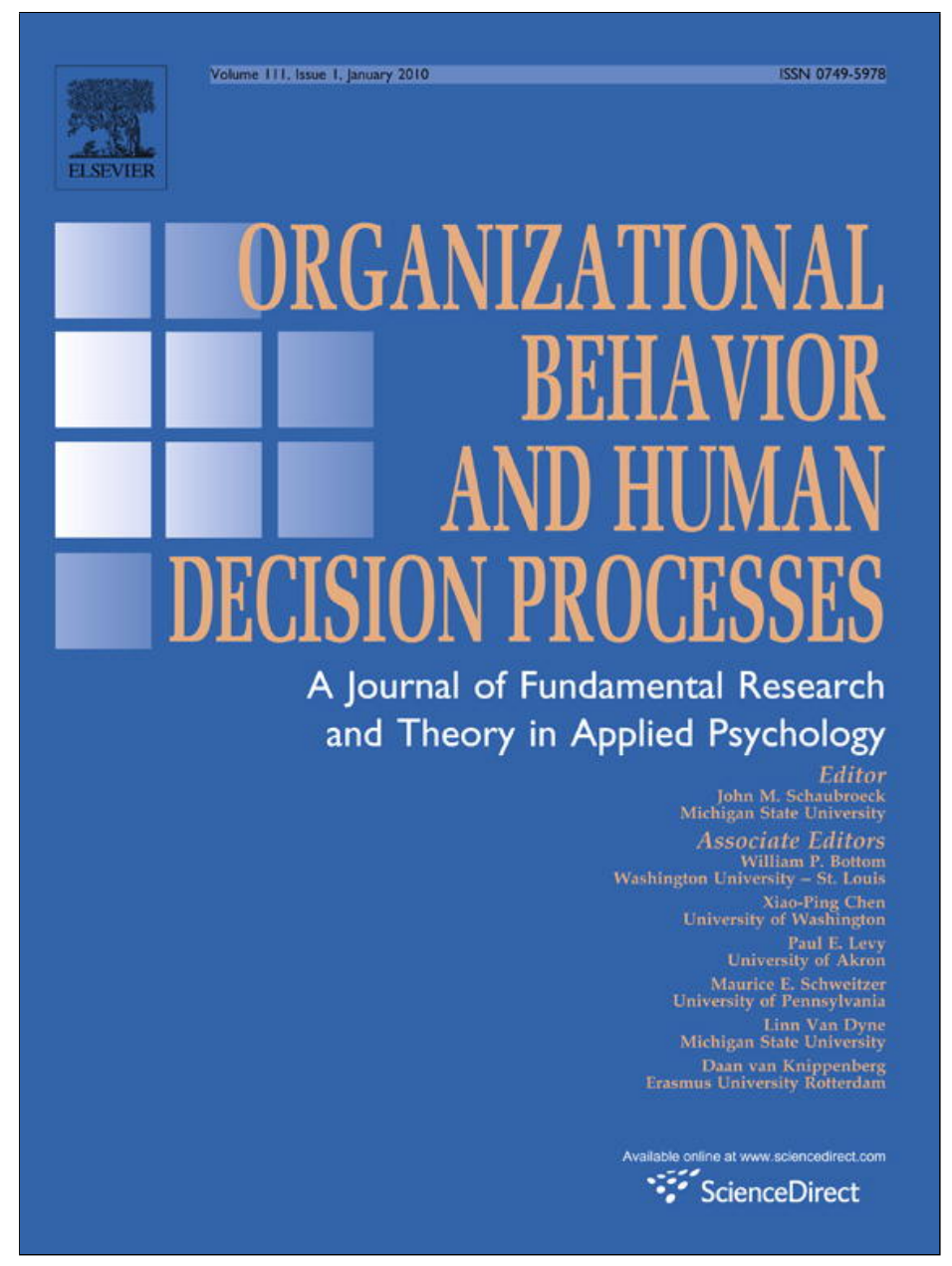

This article appeared in a journal published by Elsevier. The attached copy is furnished to the author for internal non-commercial research and education use, including for instruction at the authors institution and sharing with colleagues.

Other uses, including reproduction and distribution, or selling or licensing copies, or posting to personal, institutional or third party websites are prohibited.

In most cases authors are permitted to post their version of the article (e.g. in Word or Tex form) to their personal website or institutional repository. Authors requiring further information regarding Elsevier's archiving and manuscript policies are encouraged to visit:

http://www.elsevier.com/copyright 


\title{
Doing good buffers against feeling bad: Prosocial impact compensates for negative task and self-evaluations
}

\author{
Adam M. Grant $^{\mathrm{a}, *}$, Sabine Sonnentag ${ }^{\mathrm{b}}$ \\ ${ }^{a}$ The Wharton School, University of Pennsylvania, Philadelphia, PA, United States \\ ${ }^{\mathrm{b}}$ Department of Psychology, University of Konstanz, Germany
}

\section{A R T I C L E I N F O}

\section{Article history:}

Available online 18 August 2009

Accepted by Daan van Knippenberg

\section{Keywords:}

Prosocial impact

Helping

Affect

Burnout

\begin{abstract}
A B S T R A C T
Although evidence suggests that negative task and self-evaluations are associated with emotional exhaustion, little research has examined factors that buffer against these effects. We propose that perceived prosocial impact, the experience of helping others, compensates for negative task and self-evaluations by focusing attention on positive outcomes for others. In Study 1, perceived prosocial impact attenuated the associations of low intrinsic motivation and core self-evaluations with emotional exhaustion among professional fundraisers. Study 2 replicated these results among public sanitation employees and extended them to supervisor performance ratings. Mediated moderation analyses indicated that by protecting against emotional exhaustion, perceived prosocial impact compensated for low intrinsic motivation and core self-evaluations to predict higher performance ratings. Our studies extend theory and research on burnout, helping, and citizenship.
\end{abstract}

(c) 2009 Elsevier Inc. All rights reserved.
Emotional exhaustion, the hallmark of burnout, is a pervasive problem for organizations (Maslach, Schaufeli, \& Leiter, 2001). When employees become emotionally exhausted, they show declines in job performance, organizational citizenship behavior, and customer service (Cropanzano, Rupp, \& Byrne, 2003; Halbesleben \& Buckley, 2004; Taris, 2006), as well as increases in absenteeism and turnover (Firth \& Britton, 1989) and increased physical health risks (Melamed, Shirom, Toker, Berliner, \& Shapira, 2006). Traditionally, researchers focused heavily on the role of environmental, organizational, and situational factors in causing emotional exhaustion in service work (Halbesleben \& Buckley, 2004). More recently, scholars have shown growing interest in understanding how employees' subjective perceptions and evaluations at work are likely to influence their feelings of emotional exhaustion in a wide range of occupations, including human services, education, clerical work, computer programming, and military and managerial roles (Halbesleben \& Buckley, 2004; Maslach et al., 2001).

There is now considerable evidence that how employees evaluate their tasks and themselves has an important influence on emotional exhaustion (e.g., Best, Stapleton, \& Downey, 2005; Morrison, Payne, \& Wall, 2003). From a self-regulation perspective, negative task and self-evaluations are thought to breed emotional exhaustion by depleting employees' psychological resources (Hobfoll, 2002). When employees evaluate their tasks and themselves neg-

\footnotetext{
* Corresponding author. Tel.: +1 215746 2529; fax: +1 2158980401.

E-mail addresses: grantad@wharton.upenn.edu (A.M. Grant), sabine.sonnentag@ uni-konstanz.de (S. Sonnentag).
}

atively, they tend to dwell on unpleasant aspects of work, which consumes psychological resources, reducing their energy levels and making it more exhausting to invest time and effort in their work (Fritz \& Sonnentag, 2006). Although a number of studies have traced emotional exhaustion to negative task and self-evaluations, little theory and research exists to explain what factors buffer against the detrimental impact of these negative task and self-evaluations on emotional exhaustion. This is a theoretically and practically important problem given that researchers have generated more knowledge relevant to understanding the causes of exhaustion than the full range of factors that prevent and buffer against it (Halbesleben \& Buckley, 2004).

We address this issue by drawing on theories of self-regulation to propose that perceived prosocial impact, the experience of helping others (Grant, 2007), protects against the emotional exhaustion precipitated by negative task and self-evaluations. By focusing employees' attention on how their actions facilitate positive outcomes for others, perceived prosocial impact may reduce the likelihood that they will dwell on their negative task and selfevaluations, protecting against emotional exhaustion. We further predict that by buffering against emotional exhaustion, perceived prosocial impact enables employees to maintain their job performance. Across field studies of professional fundraisers and public sanitation employees, we find support for our buffering hypotheses that perceived prosocial impact compensates for negative task and self-evaluations, and thus protects against decreased job performance. Our research contributes to the literatures on helping, citizenship, affect, and burnout at work. 


\section{Negative task and self-evaluations and emotional exhaustion}

Our focus is on understanding contingencies that influence the impact of negative task and self-evaluations on emotional exhaustion. Emotional exhaustion is a state of affective fatigue that is characterized by low levels of energy and is experienced as psychologically aversive (for reviews, see Halbesleben \& Buckley, 2004; Maslach et al., 2001). To capture task and self-evaluations, we focus on intrinsic motivation and core self-evaluations. Intrinsic motivation is a central concept for understanding how employees evaluate their tasks. When employees are intrinsically motivated, they experience a desire to expend effort based on inherent enjoyment and interest in work tasks themselves, and when they are not intrinsically motivated, they evaluate their tasks more negatively (Gagné \& Deci, 2005; Ryan \& Deci, 2000). Core self-evaluations, a dominant concept for understanding how employees evaluate themselves, refers to the extent to which employees see their global self-concepts in a positive or negative light (Judge, Erez, Bono, \& Thoreson, 2002).

Theory and research on self-regulation and resource depletion suggest that low intrinsic motivation and core self-evaluations are likely to precipitate emotional exhaustion. Several studies have shown that when intrinsic motivation is lacking, employees are more likely to be emotionally exhausted (e.g., Jamal, 1999; Low, Cravens, Grant, \& Moncrief, 2001; Vansteenkiste et al., 2007). Since they perceive their tasks negatively and do not enjoy the process of completing them, employees who lack intrinsic motivation need to exercise self-regulation to push themselves to do so, which depletes energy, contributing to emotional exhaustion (Bolino \& Turnley, 2005; Grant, 2008a; Muraven \& Baumeister, 2000). Similarly, multiple studies have shown that employees with low core self-evaluations are more prone to emotional exhaustion (Best et al., 2005; Laschinger \& Finegan, 2008). When employees hold low core self-evaluations, they evaluate their identities and capabilities negatively, lacking self-esteem, self-efficacy, internal locus of control beliefs, and emotional stability (Judge et al., 2002). As a result, they need to exercise self-regulation to overcome their self-doubts and negative self-views, which depletes energy (e.g., Baumeister, Heatherton, \& Tice, 1993).

These bodies of research are informative in documenting how negative task and self-evaluations, in the form of low intrinsic motivation and core self-evaluations, can produce emotional exhaustion by depleting psychological resources. However, researchers have paid little attention to how employees' work experiences can buffer against the emotional exhaustion effects of low intrinsic motivation and core self-evaluations. It is to this question that we turn our attention.

\section{The buffering role of perceived prosocial impact}

We propose that the experience of helping others can buffer against the effects of negative task and self-evaluations on emotional exhaustion. Social psychologists and sociologists have begun to accumulate evidence that the experience of helping others influences affective states. In laboratory experiments, social psychologists have shown that engaging in the act of helping brings about feelings of joy and happiness (Batson, 1990; Dunn, Aknin, \& Norton, 2008; Lyubomirsky, Sheldon, \& Schkade, 2005; Williamson \& Clark, 1989) that may help to reduce negative feelings (e.g., Schaller \& Cialdini, 1988; Smith, Keating, \& Stotland, 1989). In longitudinal field studies, sociologists have found that volunteering to help, give to, and benefit others is associated with reduced depression and enhanced psychological well-being (Greenfield \& Marks, 2004; Musick \& Wilson, 2003; Penner, Dovidio, Piliavin, \& Schroeder, 2005). Economists have even acknowledged, and discovered in their own studies, that helping and giving improves happiness and psychological well-being (Brooks, 2008).

We expect that the perception of helping others, rather than the action itself, is what directly influences employees' affective states. This is important given that helping behaviors are not always appreciated by the intended beneficiaries (Penner et al., 2005). Considerable research reveals that the act of giving help can lead recipients to feel incompetent, dependent, vulnerable, threatened, embarrassed, and helpless (Fisher, Nadler, \& Whitcher-Alagna, 1982; Lee, 1997, 2002), reactions that lead to negative rather than positive states for the helper (Pines, 1982; Rosen, Mickler, \& Collins, 1987; Wills, 1978). Moreover, it is common for employees to attempt to help others but fail in providing the level or type of help that is needed (e.g., Marshall, Barnett, \& Sayer, 1997). Thus, in order to understand the affective consequences of benefiting others, it is critical to focus on employees' perceptions. To capture the perception of helping others, Grant (2007, 2008b) introduced the concept of perceived prosocial impact. Perceived prosocial impact is defined as the judgment that one's actions are beneficial to other people (Grant et al., 2007). Grant and Campbell (2007) provided initial evidence for a buffering role of perceived prosocial impact in protecting employees against emotional exhaustion caused by harming others. Building on these results, we draw on theories of self-regulation to propose that perceived prosocial impact buffers against the emotional exhaustion effects of low intrinsic motivation and core selfevaluations.

Recent developments in self-regulation theory suggest that in the process of channeling their attention and energy, individuals' self-regulation efforts can vary in whether they focus inward on themselves and their tasks or outward on others (Crocker \& Canevello, 2008; Crocker, Moeller, \& Burson, in press; Crocker, Niiya, \& Mischkowski, 2008). We propose that perceived prosocial impact shifts employees' attention outward to focus on others, rather than inward to focus on the task and the self. Indeed, research indicates that the experience of helping others promotes other-focused attention, distracting attention away from one's own problems, distresses, and frustrations (Bartel, 2001; Midlarsky, 1991). Illustrating this theme, a radiologist explains how perceived prosocial impact prevents him from becoming emotionally exhausted by focusing his attention on others:

"The reason it's important is because I make a difference. ... I am involved directly with helping to save the lives of other people. There's nothing more important on the planet ... I usually interrelate with people who are under duress ... [I think to myself,] 'Gee, I guess I could have had my arm amputated today' . and all of a sudden things come right back into perspective I'm very fortunate that I can tap any source to keep the negative from coming in" (Colby, Sippola, \& Phelps, 2001, pp. 484/ 495-496).

We predict that the other-focused attention fostered by perceived prosocial impact will protect employees with low intrinsic motivation and core self-evaluations against emotional exhaustion. When employees perceive prosocial impact, focusing on how their actions have benefited others can cultivate positive emotions such as empathic joy (Batson, 1990) and happiness (Dunn et al., 2008), which help to counteract the effects of negative feelings (Fredrickson, Mancuso, Branigan, \& Tugade, 2000) and provide a justification for stressful experiences (Grant \& Campbell, 2007; Molinsky \& Margolis, 2005). Perceived prosocial impact is thus especially likely to reduce emotional exhaustion for employees with low intrinsic motivation and core self-evaluations. When intrinsic motivation is low, employees are less intrinsically interested in and enthusiastic about the process of completing their 
tasks, and their affective states are more dependent on the outcomes that the work produces (Amabile, Hill, Hennessey, \& Tighe, 1994; Grant, 2008a). As such, when employees with low intrinsic motivation perceive prosocial impact, the joy associated with producing beneficial outcomes for others will reduce their attention to the unpleasant aspects of their tasks, reducing the likelihood of emotional exhaustion.

Similarly, when employees with low core self-evaluations perceive prosocial impact, the happiness resulting from helping others will prevent them from ruminating about their negative attributes, reducing the likelihood of emotional exhaustion. The behavioral plasticity theory of self-esteem (Brockner, 1988; see also Pierce \& Gardner, 2004) suggests that employees with low core self-evaluations will be more emotionally responsive to events and experiences than employees with high core self-evaluations. According to behavioral plasticity theory, employees with high core self-evaluations are less likely to experience negative emotional states in a wide range of situations, as they have strong coping and self-regulation skills conferred by high self-esteem, self-efficacy, emotional stability, and internal loci of control. On the other hand, the affective states of employees with low core self-evaluations are heavily influenced by and dependent on work events. Employees are more likely to experience work events negatively, and thus feel emotionally exhausted, when they have low self-esteem (Brockner, 1988), low self-efficacy (Best et al., 2005), low emotional stability (Bakker, Van Der Zee, Lewig, \& Dollard, 2006), and external loci of control (Ito \& Brotheridge, 2003). When employees perceive their actions as helping others, they feel more personally competent, as they have succeeded in benefiting others, and socially valued, as their efforts are appreciated by others (Grant, 2007, 2008b; McAdams \& de St. Aubin, 1992).

Thus, for employees with low core self-evaluations, perceived prosocial impact will provide a positive experience that counters their negative self-concepts, reducing emotional exhaustion. Emotional exhaustion is often the result of excessive focus on negative self-views (Best et al., 2005), and perceived prosocial impact can buffer against emotional exhaustion by shifting attention away from these distressing self-views and work circumstances, increasing awareness of one's fortunate circumstances (Bartel, 2001) and positive contributions to others (Midlarsky, 1991). Perceived prosocial impact may thereby play a particularly important role in protecting against emotional exhaustion for employees with low core self-evaluations. By cultivating positive emotions and focusing attention on one's contributions to others, perceived prosocial impact makes self-regulation less effortful, preventing emotional exhaustion for employees with low intrinsic motivation and core self-evaluations, who would typically find self-regulation exhausting. On the other hand, because employees with high intrinsic motivation and core self-evaluations are already focused on positive aspects of their tasks and identities, and because they already find self-regulation less effortful, perceived prosocial impact has less relevance to influencing their experiences of emotional exhaustion. We therefore predict that perceived prosocial impact weakens the negative relationships of low intrinsic motivation and core self-evaluations with emotional exhaustion.

Hypothesis 1a. Perceived prosocial impact moderates the association between low intrinsic motivation and emotional exhaustion in a compensatory fashion, such that the association becomes less negative as perceptions of prosocial impact increase.

Hypothesis 1b. Perceived prosocial impact moderates the association between low core self-evaluations and emotional exhaustion in a compensatory fashion, such that the association becomes less negative as perceptions of prosocial impact increase.

\section{Performance implications}

What are the performance implications of emotional exhaustion? A large body of empirical research has linked emotional exhaustion to decreased job performance (e.g., Cropanzano et al., 2003; Taris, 2006; Wright \& Cropanzano, 1998). When employees are emotionally exhausted, they lack the energy to complete tasks carefully (Goldberg \& Grandey, 2007) and expend additional effort in completing tasks (Halbesleben \& Bowler, 2007). For these conceptual and empirical reasons, we expect that when employees are emotionally exhausted, they will achieve lower job performance.

Hypothesis 2. Emotional exhaustion is negatively associated with job performance.

Combining our previous hypotheses, we propose that by buffering against emotional exhaustion, perceived prosocial impact will play a protective role in enabling employees to maintain their job performance even when intrinsic motivation and core selfevaluations are low. More specifically, we suggest that because perceived prosocial impact will attenuate the linkages of low intrinsic motivation and core self-evaluations with emotional exhaustion, employees with these negative task and self-evaluations will achieve greater job performance when they perceive prosocial impact.

Hypothesis 3. Emotional exhaustion mediates the moderating effects of perceived prosocial impact on the relationships of: (a) intrinsic motivation and (b) core self-evaluations with job performance.

\section{Overview of the present research}

We conducted two field studies to test our hypotheses. In Study 1 , we test Hypotheses $1 \mathrm{a}$ and $1 \mathrm{~b}$ with a sample of professional fundraisers. In Study 2, we constructively replicate this test of Hypotheses $1 \mathrm{a}$ and $1 \mathrm{~b}$ with a sample of public sanitation employees, and we also test Hypotheses 2 and 3 by obtaining supervisor ratings of job performance.

\section{Study 1}

Method

Sample and procedures

We collected data from a sample of 82 professional fundraisers working for a public university in the US. The fundraisers were employed as major gift officers responsible for soliciting multi-million dollar donations from alumni. The donations that they collected benefited others by funding scholarships for underprivileged and out-of-state students, salaries for faculty and staff members, and new buildings for the community. Over $95 \%$ of the fundraisers employed in this role responded to our survey, and they were $69.96 \%$ female with an average job tenure of 5.4 years $(S D=6.39)$.

We distributed the surveys at a staff meeting for all major gift officers across the university. The vice chancellor of the university invited them to participate in a study of burnout, and the survey contained measures of perceived prosocial impact, emotional exhaustion, the job characteristic of job autonomy, and the individual characteristics of core self-evaluations and intrinsic motivation. We protected participants' confidentiality by attending the staff meeting and collecting the surveys directly from them.

\section{Measures}

We measured all items on a 7-point Likert-type scale anchored at $1=$ disagree strongly and $7=$ agree strongly. 
Emotional exhaustion. We assessed emotional exhaustion with the 7-item scale from the Maslach Burnout Inventory (Maslach \& Jackson, 1981). A sample item is "I feel emotionally drained from my work" $(\alpha=.91)$.

Intrinsic motivation. We measured intrinsic motivation with Ryan and Connell's (1989) 4-item scale, which includes items such as "I am motivated because I enjoy the work itself" $(\alpha=.94)$.

Core self-evaluations. We assessed core self-evaluations with the 12 -item scale developed by Judge, Erez, Bono, and Thoresen (2003). A sample item is "Overall, I am satisfied with myself" $(\alpha=.83)$.

Perceived prosocial impact. We assessed perceived prosocial impact with Grant's (2008b) 3-item scale, which measures the extent to which employees feel that their work helps or benefits others. A sample item is "I feel that my work makes a positive difference in other people's lives" $(\alpha=.79)$.

Control variables. We also controlled for gender, and for job autonomy as a common predictor of burnout that has been shown to buffer against the effects of negative work experiences on emotional exhaustion (for a review, see Halbesleben \& Buckley, 2004). Controlling for job autonomy-and its interactions with intrinsic motivation and core self-evaluations-allows us to rule out the possibility that it is merely a positive experience, rather than the more specific experience of helping others, that buffers against emotional exhaustion. If a third variable such as job autonomy is responsible for the significant interactions, including one in the equation should render any moderating effects of perceived prosocial impact non-significant. To measure job autonomy, we used Morgeson and Humphrey's (2006) 9-item scale, which includes items such as "My job provides me with significant autonomy in making decisions" $(\alpha=.91)$.

\section{Results}

Means, standard deviations, and correlations are displayed in Table 1 . We tested our hypotheses using the moderated regression procedures recommended by (Aiken \& West, 1991; see also Cohen, Cohen, West, \& Aiken, 2003). We standardized intrinsic motivation, core self-evaluations, and perceived prosocial impact, multiplied the standardized variables to represent the interactions, and conducted regression analyses to examine whether the interaction terms were significant predictors of emotional exhaustion. The results of these analyses, which are displayed in Table 2, indicate that both interaction terms significantly predicted emotional exhaustion, explaining significant variance in emotional exhaustion even after controlling for gender, job autonomy, and the interactions of job autonomy with the focal variables, which were non-significant.

We took two steps to facilitate the interpretation of the significant interactions. First, we plotted the simple slopes for the relationships of intrinsic motivation and core self-evaluations with emotional exhaustion at one standard deviation above and below perceived prosocial impact. These simple slopes, which appear in Fig. 1, suggested that as hypothesized, low intrinsic motivation and core self-evaluations were associated with emotional exhaustion when perceived prosocial impact was low but not high. Second, to assess whether this observation was supported statistically, we tested whether each simple slope was significantly different from zero (Cohen et al., 2003). The relationship between intrinsic motivation and exhaustion was statistically significant when perceived prosocial impact was low, $b=-.51, S E=.18$, $\beta=-.34, t=-2.81, p<.01$, but not high, $b=.01, S E=.29, \beta=.00$, $t=.02, p=.99$. Similarly, the relationship between core self-evaluations and exhaustion was statistically significant when perceived prosocial impact was low, $b=-.84, S E=.24, \beta=-.70, t=-3.47$, $p<.01$, but not high, $b=-.11, S E=.15, \beta=-.09, t=-.74, p=.46$. Thus, in support of Hypotheses $1 \mathrm{a}$ and $1 \mathrm{~b}$, low intrinsic motivation and core self-evaluations were associated with higher levels of emotional exhaustion for employees who perceived low but not high prosocial impact.

\section{Discussion}

As predicted, perceived prosocial impact buffered against the emotional exhaustion predicted by low intrinsic motivation and core self-evaluations. However, these results are subject to important limitations. First, in order to strengthen confidence in the moderating patterns, it is necessary to replicate them in a different sample. Second, although interactions are not artificially created or inflated by common source and method effects (Evans, 1985), it is important to move beyond self-reports to examine whether emotional exhaustion has implications for job performance, as predicted in Hypotheses 2 and 3.

\section{Study 2}

\section{Method}

\section{Sample and procedures}

We collected data from a sample of 215 employees at a public sanitation plant. The plant was publicly operated and responsible for maintaining the safety and cleanliness of drinking water. The employees were engineers, technicians, electricians, inspectors, maintenance operators, programming analysts, accountants, and quality specialists. We sent electronic messages to 476 employees inviting them to complete an online survey about their work experiences, and 215 responded, yielding a response rate of $45.2 \%$. The survey asked employees to provide their supervisors' email addresses, and we sent an online survey link to supervisors, 167 of whom participated, for a response rate of $77.7 \%$. The employees were $68 \%$ male with average tenure in the organization of 14.03 years $(S D=9.94)$. The supervisors were $72.7 \%$ male with average tenure in the organization of 19.23 years $(S D=10.36)$ and an average of 4.91 years supervising the focal employees $(S D=5.71)$.

\section{Measures}

Unless otherwise indicated, all items used a 7-point Likert-type scale anchored at $1=$ disagree strongly and $7=$ agree strongly.

Table 1

Study 1: means, standard deviations, and zero-order correlations.

\begin{tabular}{llllll}
\hline & $M$ & $S D$ & 1 & 2 & \\
1. Emotional exhaustion & 2.26 & .94 & $(.91)$ & & \\
2. Perceived prosocial impact & 6.34 & .68 & -.28 & $(.79)$ & \\
3. Intrinsic motivation & 5.96 & .92 & -.36 & .45 & $(.94)$ \\
4. Core self-evaluations & 5.42 & .74 & -.31 & .20 & .32 \\
5. Autonomy & 6.04 & .71 & -.33 & .30 & $(.83)$ \\
\hline
\end{tabular}

Note: $r \geqslant .21, p<.05$ and $r \geqslant .29, p<.01$. 
Table 2

Study 1: moderated regression analyses predicting emotional exhaustion.

\begin{tabular}{|c|c|c|c|c|c|c|c|c|}
\hline & \multicolumn{4}{|l|}{ Step 1} & \multicolumn{4}{|c|}{ Step 2} \\
\hline & $b$ & $S E$ & $\beta$ & $t(70)$ & $b$ & $S E$ & $\beta$ & $t(68)$ \\
\hline Autonomy & -.22 & .21 & -.14 & -1.04 & -.37 & .21 & -.23 & -1.76 \\
\hline Gender & .36 & .27 & .14 & 1.36 & .31 & .25 & .12 & 1.24 \\
\hline Intrinsic motivation & -.13 & .23 & -.09 & -.55 & .06 & .24 & .04 & .27 \\
\hline Core self-evaluations & -.17 & .15 & -.14 & -1.12 & -.35 & .15 & -.30 & $-2.33^{*}$ \\
\hline Perceived prosocial impact & -.08 & .14 & -.07 & -.55 & -.06 & .14 & -.05 & -.42 \\
\hline Autonomy $\times$ intrinsic motivation & -.39 & .23 & -.27 & -1.71 & -.25 & .22 & -.17 & -1.12 \\
\hline Autonomy $\times$ core self-evaluations & .03 & .18 & .02 & .17 & .01 & .17 & .01 & .06 \\
\hline Autonomy $\times$ perceived prosocial impact & .16 & .12 & .20 & 1.31 & .04 & .12 & .05 & .33 \\
\hline Intrinsic motivation $\times$ perceived prosocial impact & & & & & .31 & .15 & .27 & $2.07^{*}$ \\
\hline Core self-evaluations $\times$ perceived prosocial impact & & & & & .30 & .15 & .24 & $2.04^{*}$ \\
\hline
\end{tabular}

Notes: The inclusion of the focal interactions in Step 2 increased variance explained significantly by $9 \%$ from $R^{2}=.28$ to $R^{2}=.37, F(2,68)=5.21, p<.01$. We also ran hierarchical regressions to examine the incremental variance explained by each interaction. The partialed product terms explained incremental variance in emotional exhaustion of $4 \%$ for intrinsic motivation, $F(1,68)=4.30, p<.05$ and $4 \%$ for core self-evaluations, $F(1,68)=4.18, p<.05$.

* $p<.05$.

Job performance. Supervisors rated employees' overall performance using a 5-item scale from Ashford and Black (1996). The statement asked, "Please recall this employee's last actual performance evaluation and report how she/he was rated relative to others." We chose this focus because supervisors completed their surveys during the same month that performance evaluations had been conducted across the plant. The items, which used a 9-point scale anchored at $1=$ bottom $10 \%$ and $9=$ top $10 \%$, included "achievement of work goals" and "overall performance" $(\alpha=.95)$.
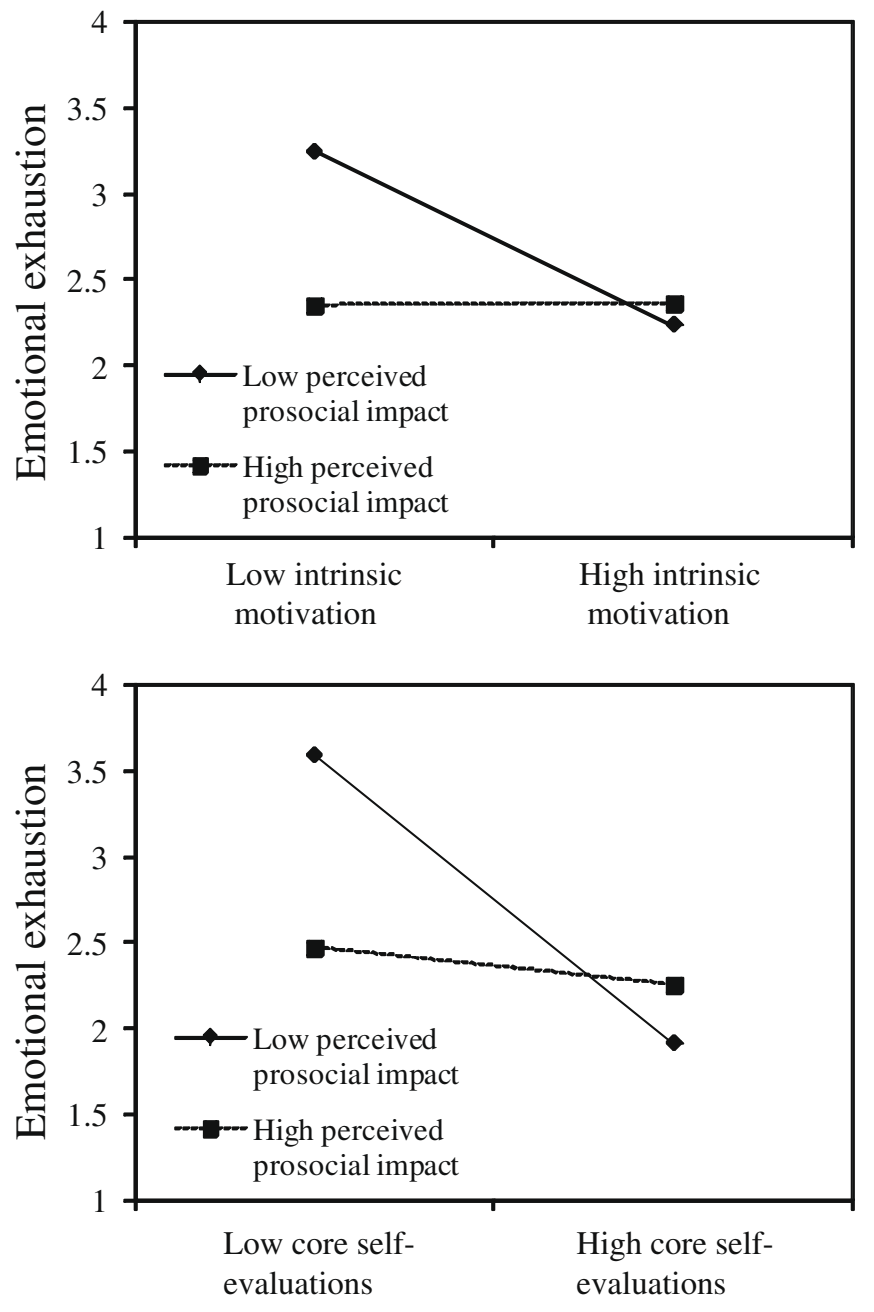

Fig. 1. Study 1: regression slopes.
Emotional exhaustion. Employees reported their emotional exhaustion on the same 7-item scale (Maslach \& Jackson, 1981) as in Study $1(\alpha=.90)$.

Intrinsic motivation. Employees reported their intrinsic motivation on the same scale (Ryan \& Connell, 1989) as in Study $1(\alpha=.92)$.

Core self-evaluations. Employees reported their core self-evaluations on the same 12-item scale (Judge et al., 2003) as in Study 1 $(\alpha=.80)$.

Perceived prosocial impact. Employees reported their perceptions of prosocial impact on the same 3-item scale (Grant, 2008b) as in Study $1(\alpha=.95)$.

\section{Results and discussion}

Table 3 displays means, standard deviations, and correlations. In support of Hypothesis 2, emotional exhaustion was associated with lower supervisor performance ratings. As in the previous study, we tested our moderating hypotheses using moderated regression procedures (Aiken \& West, 1991; Cohen et al., 2003). Table 4 displays the results of these analyses; once again, both interaction terms explained significant variance in emotional exhaustion. The interaction terms also explained significant variance in supervisor performance ratings. The simple slopes, which are displayed in Figs. 2 and 3, suggest that low intrinsic motivation and core self-evaluations were more likely to be associated with higher emotional exhaustion and lower supervisor performance ratings when perceived prosocial impact was low rather than high. These interpretations are generally supported statistically by simple slope tests, which appear in Table 5.

To test our moderated mediation hypothesis, we used the moderated path analysis framework developed by Edwards and Lambert (2007). Our hypotheses represent a first-stage moderation model, as the relationships of intrinsic motivation and core selfevaluations with the mediator of emotional exhaustion are moderated by perceived prosocial impact, and then the mediator of emotional exhaustion is directly related to the outcome of job performance. We used bootstrap procedures to draw 1000 random samples with replacement from the full sample, which allowed us to constructed bias-corrected confidence intervals (Edwards \& Lambert, 2007; MacKinnon, Fairchild, \& Fritz, 2007). The confidence intervals excluded zero for the sizes of the indirect effects of the interactions of perceived prosocial impact with both intrinsic motivation $(-.01,-.13)$ and core self-evaluations $(-.01,-.11)$ on supervisor performance evaluations through emotional exhaustion. In addition, as displayed in Table 6 , the moderating effect 
Table 3

Study 2: means, standard deviations, and zero-order correlations.

\begin{tabular}{|c|c|c|c|c|c|c|c|}
\hline & $M$ & $S D$ & 1 & 2 & 3 & 4 & 5 \\
\hline 1. Emotional exhaustion & 2.79 & 1.10 & $(.90)$ & & & & \\
\hline 2. Supervisor performance ratings & 7.90 & 1.33 & -.26 & $(.95)$ & & & \\
\hline 3. Perceived prosocial impact & 5.35 & 1.12 & -.19 & .04 & $(.95)$ & & \\
\hline 4. Core self-evaluations & 5.32 & .71 & -.38 & .08 & .30 & $(.80)$ & \\
\hline 5. Intrinsic motivation & 5.55 & 1.12 & -.45 & .17 & .28 & .25 & $(.92)$ \\
\hline
\end{tabular}

Note: $r \geqslant .14, p<.05$ and $r \geqslant .18, p<.01$

occurred only at the first stage, and not at the second stage. These results support Hypotheses $3 \mathrm{a}$ and $3 \mathrm{~b}$ showing that emotional exhaustion mediated the moderating effect of perceived prosocial impact on the relationships of intrinsic motivation and core selfevaluations with performance.

\section{General discussion}

Across two studies, we found that perceived prosocial impact buffered against emotional exhaustion predicted by low intrinsic motivation and core self-evaluations. Our findings offer several important implications for theory and research on helping, citizenship, affect, and performance at work.

\section{Theoretical contributions}

Our central contribution lies in introducing the experience of helping others as a buffer against the emotional exhaustion costs of negative task and self-evaluations. Our hypotheses and results advance a compensatory perspective on the role of perceived prosocial impact in emotional exhaustion. Rather than assuming that the experience of doing good will always protect against feeling bad, we examined how this buffering effect would be stronger for employees who lacked intrinsic motivation and high core self-evaluations. These findings provide new insights into when and for whom doing good buffers against feeling bad, revealing that perceived prosocial impact is particularly important to protecting against negative affective experiences for employees who hold negative perceptions of their tasks and identities.

In addition, our research demonstrates that by protecting against emotional exhaustion, perceived prosocial impact can en- able employees to maintain high levels of job performance even when intrinsic motivation and core self-evaluations are low. These findings suggest that a focus on benefiting others may play a critical role in enabling employees who have negative task and individual perceptions to perform effectively. These findings take a much-needed step toward considering the possibility that prosocial, other-focused psychological states may reduce emotional exhaustion and enhance performance by shifting attention away from negative self-evaluations and task evaluations.

Finally, by examining the affective implications of the experience of helping others, our research reverses the relationship between helping and affect. Extensive research has shown that positive affect tends to increase helping, citizenship, and prosocial behaviors directed toward benefiting others (e.g., Carlson, Charlin, \& Miller, 1998; George \& Brief, 1992; Lee \& Allen, 2002). However sparse research has examined how the experience of helping others influences employees' affective states. Our research suggests that the experience of helping others may play an important buffering role in protecting against negative affective experiences.

\section{Limitations and future directions}

Our research is subject to a number of limitations that point to fruitful directions for future research. First, in focusing on our buffering hypotheses, we did not attend to a competing amplification perspective, which proposes that perceived prosocial impact will enhance the benefits of intrinsic motivation and core self-evaluations. For example, self-verification theory (Swann, Polzer, Seyle, \& Ko, 2004) suggests that employees with high core self-evaluations may be more cognitively and emotionally receptive to the perception of prosocial impact, as it is congruent with their positive self-concepts, while employees with low core self-evaluations

Table 4

Study 2: moderated regression analyses.

\begin{tabular}{|c|c|c|c|c|c|c|c|c|c|c|c|c|c|c|c|c|}
\hline & \multicolumn{8}{|c|}{ DV: emotional exhaustion } & \multicolumn{8}{|c|}{ DV: supervisor performance ratings } \\
\hline & \multicolumn{4}{|c|}{ Step 1} & \multicolumn{4}{|c|}{ Step 2} & \multicolumn{4}{|c|}{ Step 1} & \multicolumn{4}{|c|}{ Step 2} \\
\hline & $b$ & $S E$ & $\beta$ & $t$ & $b$ & $S E$ & $\beta$ & $t$ & $b$ & SE & $\beta$ & $t$ & $b$ & $S E$ & $\beta$ & $t$ \\
\hline Intrinsic motivation & -.35 & .07 & -.29 & $-4.66^{* * *}$ & -.30 & .08 & -.25 & $-3.98^{* * *}$ & .05 & .11 & .04 & .46 & .01 & .11 & .01 & .11 \\
\hline Core self-evaluations & -.43 & .07 & -.36 & $-5.99^{* * *}$ & -.43 & .07 & -.37 & $-6.14^{* * *}$ & .29 & .11 & .22 & $2.72^{* *}$ & .19 & .11 & .15 & 1.72 \\
\hline Perceived prosocial impact & -.05 & .07 & -.05 & -.77 & -.05 & .07 & -.04 & -.66 & .15 & .11 & .11 & 1.37 & .13 & .11 & .10 & 1.20 \\
\hline $\begin{array}{l}\text { Intrinsic motivation X Perceived prosocial } \\
\text { impact }\end{array}$ & & & & & .20 & .08 & .16 & $2.70^{* *}$ & -.27 & .12 & -.19 & $-2.33^{*}$ & -.25 & .12 & -.17 & $-2.04^{*}$ \\
\hline $\begin{array}{l}\text { Core self-evaluations X Perceived prosocial } \\
\text { impact }\end{array}$ & & & & & .15 & .08 & .12 & $1.99^{*}$ & -.30 & .12 & -.19 & -2.49 & -.31 & .13 & -.20 & $-2.36^{*}$ \\
\hline Emotional exhaustion & & & & & & & & & & & & & -.24 & .11 & -.21 & $-2.30 *$ \\
\hline $\begin{array}{l}\text { Emotional exhaustion X Perceived prosocial } \\
\text { impact }\end{array}$ & & & & & & & & & & & & & -.10 & .12 & -.07 & -.78 \\
\hline
\end{tabular}

Notes: The inclusion of the interactions in Step 2 increased variance explained significantly in emotional exhaustion by $4 \%$, from $R^{2}=.28$ to $R^{2}=.32, F(2,208)=6.79, p<.01$ The partialed product terms explained incremental variance in emotional exhaustion of $2 \%$ for intrinsic motivation, $F(1,208)=7.30, p<.01$, and $2 \%$ for core self-evaluations, $F(1,208)=3.95, p<.05$. They explained incremental variance in supervisor performance ratings of $4 \%$ for intrinsic motivation, $F(1,160)=6.19, p<.05$, and $3 \%$ for core selfevaluations, $F(1,160)=5.13, p<.05$. Emotional exhaustion explained an additional $3 \%$ of variance in supervisor performance ratings, increasing variance explained to $R^{2}=.19$, $F(1,59)=5.30, p<.05$

* $p<.05$.

** $p<.01$.

$p<.001$. 

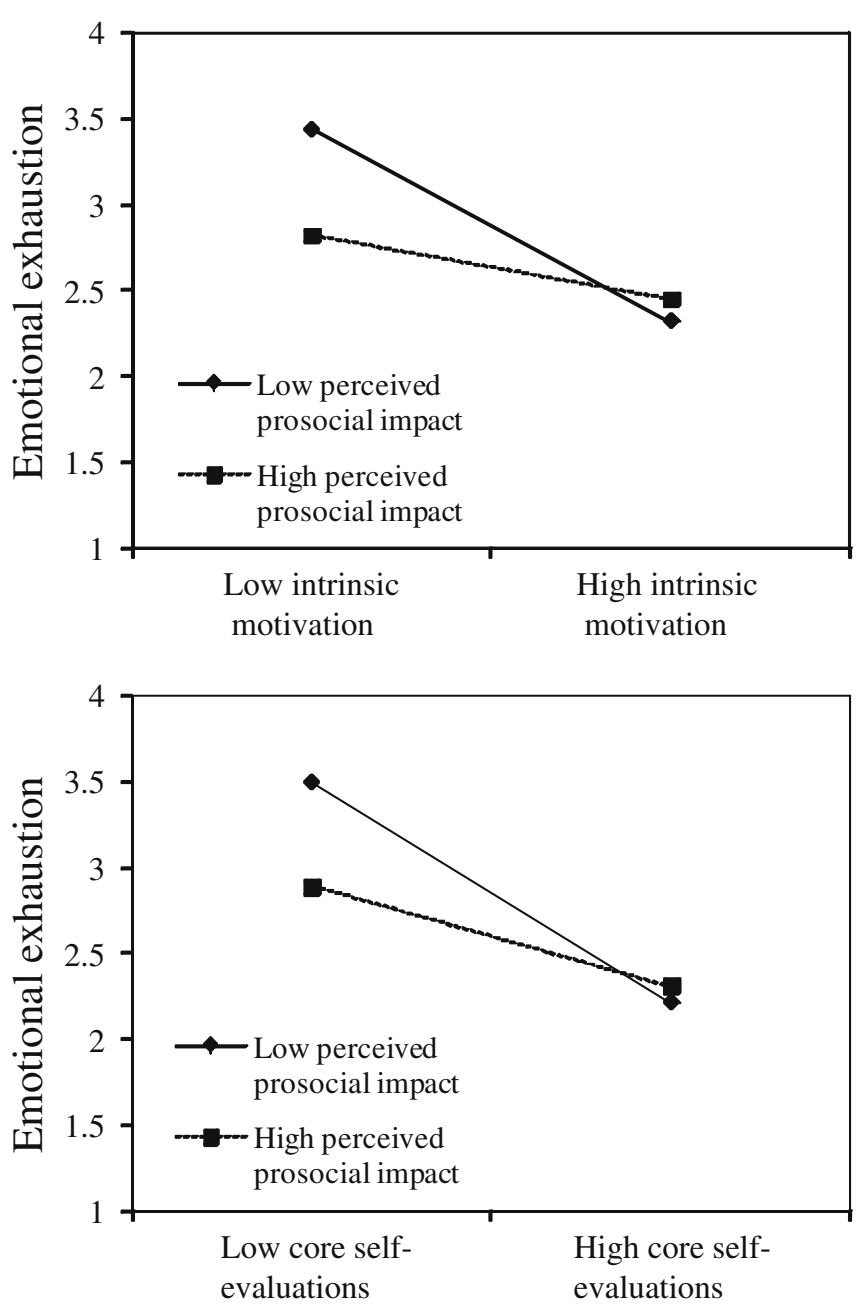

Fig. 2. Study 2: regression slopes for emotional exhaustion.

may resist this perception of prosocial impact, because it does not affirm their self-concepts. Similarly, theories of trait-congruent affect (Moskowitz \& Coté, 1995) and trait activation (Tett \& Guterman, 2000) suggest that the positive affective experience of prosocial impact may encourage employees with high core selfevaluations and intrinsic motivation to express these positive affect-laden traits and thereby reduce their own emotional exhaustion, while employees with low core self-evaluations and intrinsic motivation are less likely to experience positive emotions that counter emotional exhaustion (Fredrickson et al., 2000). Future research will be necessary to identify conditions under which this amplification pattern emerges in place of the compensation perspective.

Second, we focused on emotional exhaustion as a mediator of the relationship between perceived prosocial impact and job performance, but we did not explore the mechanisms that mediate the relationship between perceived prosocial impact and emotional exhaustion. We hope to see researchers directly test our explanation that perceived prosocial impact facilitates self-regulation by distracting attention away from frustrations, as well as the possibilities that perceived prosocial impact affirms and strengthens employees' identities as capable contributors (Grube \& Piliavin, 2000) or socially responsible citizens (Colby et al., 2001; Fleeson, 2001 ), or protects against existential anxiety about their contributions (McAdams \& de St. Aubin, 1992). Third, although we obtained supervisor performance ratings in Study 2, it is possible that supervisors based their judgments not on observing poorer contribu-
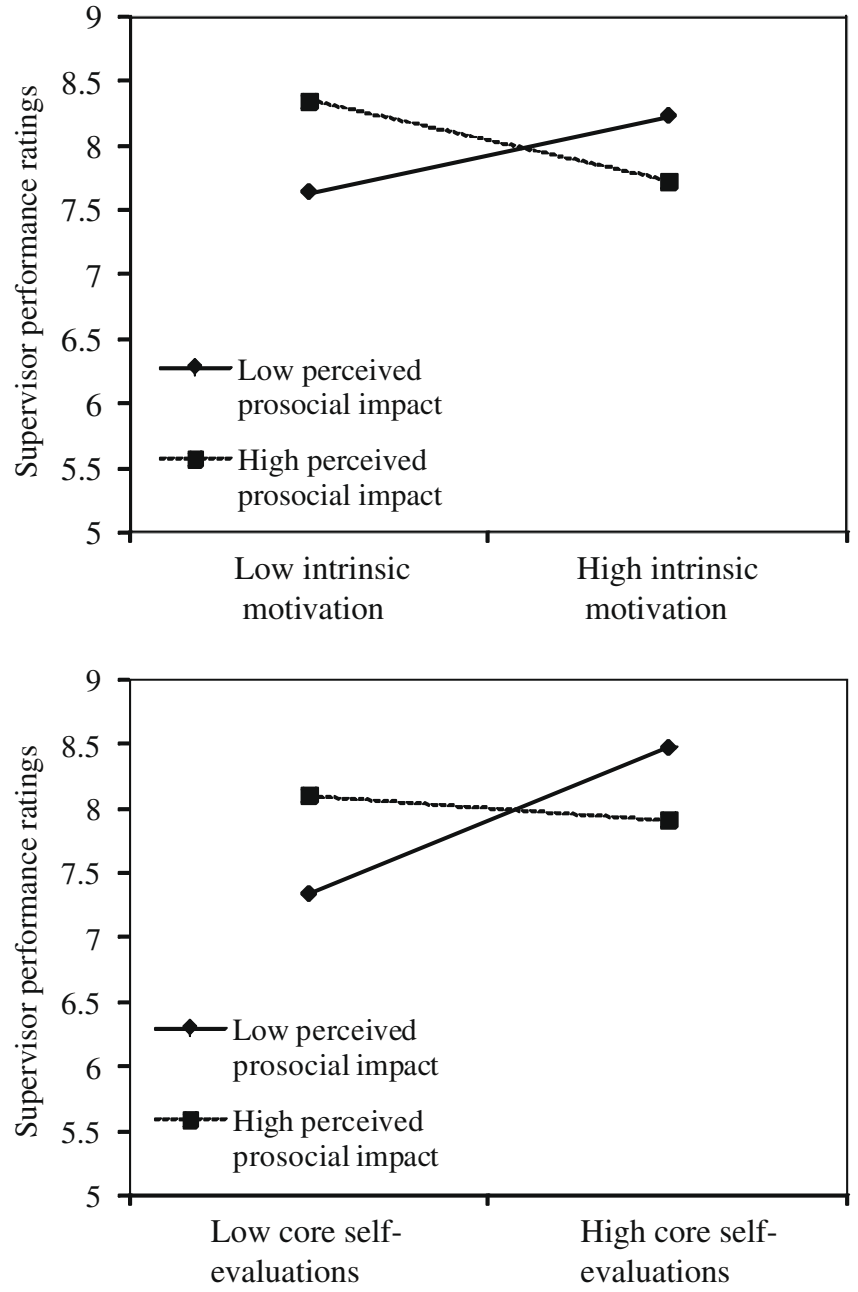

Fig. 3. Study 2: regression slopes for supervisor performance ratings.

tions, but rather on interpreting emotional exhaustion itself as a signal of disengagement. Organizational researchers specializing in affect have called for more efforts to link affective states to independent measures such as objective behaviors, verbal and nonverbal communications, and physiological data (Brief \& Weiss, 2002). It will be important in future research to triangulate self-reports and supervisor ratings with these types of measures, which tend to be more robust against biases.

Fourth, since we did not experimentally manipulate our predictor variables or collect longitudinal data, alternative causal paths are possible. For example, it may be the case that emotional exhaustion reduces perceptions of prosocial impact by draining the energy available for contributing to and helping others, and that this effect is stronger for employees who lack high core selfevaluations or intrinsic motivation to energize them. In addition, it is possible that poor performance is a cause, not only a consequence, of emotional exhaustion. We hope to see experimental and longitudinal studies address this issue of reverse causation. Fifth, in focusing on employees' perceptions of prosocial impact, we did not examine recipients' reactions. We encourage researchers to investigate whether negative feedback from recipients weakens the buffering effect of perceived prosocial impact on emotional exhaustion by causing employees to experience guilt or cognitive dissonance. Finally, we focused on emotional exhaustion rather than studying multiple affective states or discrete emotions. Organizational scholars have repeatedly called for researchers to study specific, discrete emotions rather than more general levels of posi- 
Table 5

Study 2: simple slope tests.

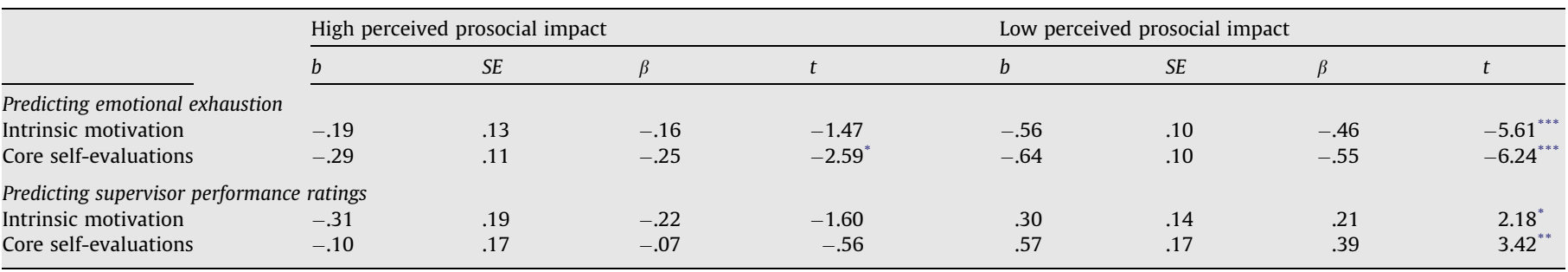

** $p<.05$.

$p<.001$

Table 6

Moderated mediation analysis of simple effects.

\begin{tabular}{|c|c|c|c|c|c|}
\hline \multirow[t]{2}{*}{ Predictor variable } & \multicolumn{2}{|l|}{ Stage } & \multicolumn{3}{|l|}{ Effect } \\
\hline & First & Second & Direct & Indirect & Total \\
\hline \multicolumn{6}{|l|}{ Intrinsic motivation } \\
\hline Low perceived prosocial impact & $-.50^{*}$ & -.15 & .26 & .07 & .33 \\
\hline High perceived prosocial impact & -.10 & -.34 & -.24 & .03 & -.20 \\
\hline Differences & $.40^{*}$ & -.19 & -.50 & -.04 & -.54 \\
\hline \multicolumn{6}{|l|}{ Core self-evaluations } \\
\hline Low perceived prosocial impact & $-.58^{*}$ & -.15 & .26 & .09 & .35 \\
\hline High perceived prosocial impact & $-.28^{*}$ & $-.34^{*}$ & $-.24^{*}$ & $.10^{*}$ & -.14 \\
\hline Differences & $.30^{*}$ & -.19 & -.50 & .01 & -.49 \\
\hline
\end{tabular}

* $p<.05$

tive and negative affect (Brief \& Weiss, 2002; Brockner \& Higgins, 2001; Lee \& Allen, 2002). We recommend that researchers address this issue by conducting more nuanced investigations of whether perceptions of prosocial impact are differentially associated with different emotions. For example, because perceived prosocial impact involves an awareness of the self as impacting other people (Grant \& Campbell, 2007), it may have a particularly potent influence on social, self-relevant emotions such as gratitude, guilt, and pride. In addition, it will be important to examine whether our findings are circumscribed to emotional exhaustion, or whether similar results will emerge for positive emotional states (see Greenfield \& Marks, 2004). Given the independence of positive and negative affect, it is quite possible that the effects will not be symmetric.

\section{Practical implications and conclusion}

Our research offers meaningful insights for managers and employees. Our moderating results suggest that the experience of prosocial impact may be especially important for employees who lack positive feelings about themselves and intrinsic enjoyment of their tasks. These findings suggest that interventions to enrich employees' experiences of task significance and contact with beneficiaries-both of which can increase perceptions of prosocial impact (Grant, 2008b; Grant et al., 2007)-may prove valuable in preventing against burnout for those who lack high intrinsic motivation or core self-evaluations. For these employees, managers may be able to protect against emotional exhaustion by providing opportunities to help others and see how their help benefits others. Managers may also wish to use stories to remind employees of the ways in which their actions are benefiting others (e.g., Grant, 2008b; Hackman \& Oldham, 1976; Piccolo \& Colquitt, 2006). On the same token, these findings suggest that employees with low intrinsic motivation and core self-evaluations may benefit from crafting their jobs (Wrzesniewski \& Dutton, 2001) to help others. In conclusion, Ralph Waldo Emerson once wrote, "It is one of the most beautiful compensations of life that no man can sincerely try to help another without helping himself." Our research qualifies this statement by suggesting that it is more likely to hold true for individuals who lack positive evaluations of their tasks and themselves.

\section{Acknowledgments}

For helpful feedback on previous drafts, we are grateful to Associate Editor Daan van Knippenberg, three anonymous reviewers, Carmen Binnewies, and Peter Totterdell. For help with data collection, we thank Rebecca Bramlett, Beth Braxton, Elizabeth Dunn, Andy Duvall, Ted Henifin, Matt Kupec, Nora Llabona, Lauren Malcolm, and Andi Sobbe.

\section{References}

Aiken, L. S., \& West, S. G. (1991). Multiple regression: Testing and interpreting interactions. Newbury Park, CA: Sage.

Amabile, T. M., Hill, K. G., Hennessey, B. A., \& Tighe, E. M. (1994). The work preference inventory: Assessing intrinsic and extrinsic motivational orientations. Journal of Personality and Social Psychology, 66, 950-967.

Ashford, S. J., \& Black, J. S. (1996). Proactivity during organizational entry: Antecedents, tactics, and outcomes. Journal of Applied Psychology, 81, 199-214.

Bakker, A. B., Van Der Zee, K. I., Lewig, K. A., \& Dollard, M. F. (2006). The relationship between the Big Five personality factors and burnout: A study among volunteer counselors. Journal of Social Psychology, 146, 31-50.

Bartel, C. A. (2001). Social comparisons in boundary-spanning work: Effects of community outreach on members' organizational identity and identification. Administrative Science Quarterly, 46, 379-413.

Batson, C. D. (1990). How social an animal? The human capacity for caring. American Psychologist, 45, 336-346.

Baumeister, R. F., Heatherton, T. F., \& Tice, D. M. (1993). When ego threats lead to self-regulation failure: Negative consequences of high self-esteem. Journal of Personality and Social Psychology, 64, 141-156.

Best, R. G., Stapleton, L. M., \& Downey, R. G. (2005). Core self-evaluations and job burnout: The test of alternative models. Journal of Occupational Health Psychology, 10, 441-451.

Bolino, M. C. \& Turnley, W. H. (2005). The personal costs of citizenship behavior: The relationship between individual initiative and role overload, job stress, and work-family conflict. Journal of Applied Psychology, 90, 740-748.

Brief, A. P., \& Weiss, H. M. (2002). Organizational behavior: Affect in the workplace. Annual Review of Psychology, 53, 279-307.

Brockner, J. (1988). Self-esteem at work: Research, theory and practice. Lexington, MA: D.C. Heath \& Co.

Brockner, J., \& Higgins, E. T. (2001). Regulatory focus theory: Its implications for the study of emotions in the workplace. Organizational Behavior and Human Decision Processes, 86, 35-66.

Brooks, A. C. (2008). Gross national happiness: Why happiness matters for AmericaAnd how we can get more of it. New York: Basic Books.

Carlson, M., Charlin, V., \& Miller, N. (1988). Positive mood and helping behavior: A test of six hypotheses. Journal of Personality and Social Psychology, 55, 211-229.

Cohen, J., Cohen, P., West, S. G., \& Aiken, L. S. (2003). Applied multiple regression/ correlation analysis for the behavioral sciences (3rd ed.). Mahwah, NJ: Lawrence Erlbaum Associates.

Colby, A., Sippola, L., \& Phelps, E. (2001). Social responsibility and paid work in contemporary American life. In A. S. Rossi (Ed.), Caring and doing for others: Social responsibility in the domains of family, work, and community (pp. 463-501). Chicago: University of Chicago Press. 
Crocker, J., \& Canevello, A. (2008). Creating and undermining social support in communal relationships: The role of compassionate and self-image goals. Journal of Personality and Social Psychology, 95, 555-575.

Crocker, J., Moeller, S., \& Burson, A. (in press). The costly pursuit of self-esteem: Implications for self-regulation. In R. Hoyle (Ed.), Handbook of personality and self-regulation.

Crocker, J., Niiya, Y., \& Mischkowski, D. (2008). Why does writing about important values reduce defensiveness? Self-affirmation and the role of positive otherdirected feelings. Psychological Science, 19, 740-747.

Cropanzano, R., Rupp, D. E., \& Byrne, Z. S. (2003). The relationship of emotional exhaustion to work attitudes, job performance, and organizational citizenship behaviors. Journal of Applied Psychology, 88, 160-169.

Dunn, E. W., Aknin, L. B., \& Norton, M. I. (2008). Spending money on others promotes happiness. Science, 319, 1687-1688.

Edwards, J. R., \& Lambert, L. S. L. (2007). Methods for integrating moderation and mediation: A general analytical framework using moderated path analysis. Psychological Methods, 12, 1-22.

Evans, M. G. (1985). A Monte Carlo study of the effects of correlated method variance in moderated multiple regression analysis. Organizational Behavior and Human Decision Processes, 36, 305-323.

Firth, H., \& Britton, P. (1989). Burnout, absence and turnover amongst British nursing staff. Journal of Occupational Psychology, 62, 55-60.

Fisher, J. D., Nadler, A., \& Whitcher-Alagna, S. (1982). Recipient reactions to aid. Psychological Bulletin, 91, 27-54.

Fleeson, W. (2001). Judgments of one's own global contributions to the welfare of others: Life-course trajectories and predictors. In A. S. Rossi (Ed.), Caring and doing for others: Social responsibility in the domains of family, work, and community (pp. 75-96). Chicago: University of Chicago Press.

Fredrickson, B. L., Mancuso, R. A., Branigan, C., \& Tugade, M. M. (2000). The undoing effect of positive emotions. Motivation and Emotion, 24, 237-258.

Fritz, C., \& Sonnentag, S. (2006). Recovery, well-being, and performance-related outcomes: The role of workload and vacation experiences. Journal of Applied Psychology, 91, 936-945.

Gagné, M., \& Deci, E. L. (2005). Self-determination theory and work motivation. Journal of Organizational Behavior, 26, 331-362.

George, J. M., \& Brief, A. P. (1992). Feeling good-Doing good: A conceptual analysis of the mood at work-Organizational spontaneity relationship. Psychological Bulletin, 112, 310-329.

Goldberg, L. S., \& Grandey, A. A. (2007). Display rules versus display autonomy: Emotion regulation, emotional exhaustion, and task performance in a call center simulation. Journal of Occupational Health Psychology, 12, 301-318.

Grant, A. M. (2007). Relational job design and the motivation to make a prosocial difference. Academy of Management Review, 32, 393-417.

Grant, A. M. (2008a). Does intrinsic motivation fuel the prosocial fire? Motivational synergy in predicting persistence, performance, and productivity. Journal of Applied Psychology, 93, 48-58.

Grant, A. M. (2008b). The significance of task significance: Job performance effects, relational mechanisms, and boundary conditions. Journal of Applied Psychology, 93, 108-124.

Grant, A. M., \& Campbell, E. M. (2007). Doing good, doing harm, being well and burning out: The interactions of perceived prosocial and antisocial impact in service work. Journal of Occupational and Organizational Psychology, 80, 665-691.

Grant, A. M., Campbell, E. M., Chen, G., Cottone, K. Lapedis, D., \& Lee, K. (2007) Impact and the art of motivation maintenance: The effects of contact with beneficiaries on persistence behavior. Organizational Behavior and Human Decision Processes, 103, 53-67.

Greenfield, E. A., \& Marks, N. F. (2004). Formal volunteering as a protective factor for older adults' psychological well-being. Journals of Gerontology, Series B: Psychological Sciences and Social Sciences, 59, S258-S264.

Grube, J. A., \& Piliavin, J. A. (2000). Role identity, organizational experiences, and volunteer performance. Personality and Social Psychology Bulletin, 26, $1108-1119$.

Hackman, J. R., \& Oldham, G. R. (1976). Motivation through the design of work: Test of a theory. Organizational Behavior and Human Performance, 16, 250-279.

Halbesleben, J. R. B., \& Bowler, W. M. (2007). Emotional exhaustion and job performance: The mediating role of motivation. Journal of Applied Psychology, 92, 93-106.

Halbesleben, J. R. B., \& Buckley, R. M. (2004). Burnout in organizational life. Journal of Management, 30, 859-879.

Hobfoll, S. E. (2002). Social and psychological resources and adaptation. Review of General Psychology, 6, 307-324.

Ito, J. K., \& Brotheridge, C. M. (2003). Resources, coping strategies, and emotional exhaustion: A conservation of resources perspective. Journal of Vocational Behavior, 63, 490-509.

Jamal, M. (1999). Job stress and employee well-being: A cross-cultural empirical study. Stress Medicine, 15, 153-158.

Judge, T. A., Erez, A., Bono, J. E., \& Thoresen, C. J. (2003). The core self-evaluations scale: Development of a measure. Personnel Psychology, 56, 303-331.

Judge, T. A., Erez, A., Bono, J. E., \& Thoreson, C. J. (2002). Are measures of self-esteem, neuroticism, locus of control, and generalized self-efficacy indicators of a common core construct? Journal of Personality and Social Psychology, 83, $693-710$.

Laschinger, H. K. S., \& Finegan, J. (2008). Situational and dispositional predictors of nurse manager burnout: A time-lagged analysis. Journal of Nursing Management, $16,601-607$.
Lee, F. (1997). When the going gets tough, do the tough ask for help? Help seeking and power motivation in organizations. Organizational Behavior and Human Decision Processes, 72, 336-363.

Lee, F. (2002). The social costs of seeking help. Journal of Applied Behavioral Science, $38,17-35$.

Lee, K., \& Allen, N. J. (2002). Organizational citizenship behavior and workplace deviance: The role of affect and cognitions. Journal of Applied Psychology, 87, 131-142.

Low, G. S., Cravens, D. W., Grant, K., \& Moncrief, W. C. (2001). Antecedents and consequences of salesperson burnout. European Journal of Marketing, 35, 587-611.

Lyubomirsky, S., Sheldon, K. M., \& Schkade, D. (2005). Pursuing happiness: The architecture of sustainable change. Review of General Psychology, 9, 111-131.

MacKinnon, D. P., Fairchild, A. J., \& Fritz, M. S. (2007). Mediation analysis. Annual Review of Psychology, 58, 593-614.

Marshall, N. L., Barnett, R. C., \& Sayer, A. (1997). The changing workforce, job stress, and psychological distress. Journal of Occupational Health Psychology, 2, 99-107.

Maslach, C., \& Jackson, S. E. (1981). The Maslach burnout inventory manual. Palo Alto, CA: Consulting Psychologists Press.

Maslach, C., Schaufeli, W. B., \& Leiter, M. P. (2001). Job burnout. Annual Review of Psychology, 52, 397-422.

McAdams, D. P., \& de St. Aubin, E. (1992). A theory of generativity and its assessment through self-report, behavioral acts, and narrative themes in autobiography. Journal of Personality and Social Psychology, 62, 1003-1015.

Melamed, S., Shirom, A., Toker, S., Berliner, S., \& Shapira, I. (2006). Burnout and risk of cardiovascular disease: Evidence, possible causal paths, and promising research directions. Psychological Bulletin, 132, 327-353.

Midlarsky, E. (1991). Helping as coping. In M. S. Clark (Ed.), Prosocial behavior (pp. 238-264). Thousand Oaks, CA: Sage.

Molinsky, A., \& Margolis, J. (2005). Necessary evils and interpersonal sensitivity in organizations. Academy of Management Review, 30, 245-268.

Morgeson, F. P., \& Humphrey, S. E. (2006). The work design questionnaire (WDQ): Developing and validating a comprehensive measure for assessing job design and the nature of work. Journal of Applied Psychology, 91, 1321-1339.

Morrison, D., Payne, R. L., \& Wall, T. D. (2003). Is job a viable unit of analysis? A multilevel analysis of demand-control-support models. Journal of Occupational Health Psychology, 8, 209-219.

Moskowitz, D. S., \& Coté, S. (1995). Do interpersonal traits predict affect? A comparison of three models. Journal of Personality and Social Psychology, 69, 915-924.

Muraven, M., \& Baumeister, R. F. (2000). Self-regulation and depletion of limited resources: Does self-control resemble a muscle? Psychological Bulletin, 126, 247-259.

Musick, M. A., \& Wilson, J. (2003). Volunteering and depression: The role of psychological and social resources in different age groups. Social Science and Medicine, 56, 259-269.

Penner, L. A., Dovidio, J. F., Piliavin, J. A., \& Schroeder, D. A. (2005). Prosocial behavior: Multilevel perspectives. Annual Review of Psychology, 56, 365-392.

Piccolo, R. F., \& Colquitt, J. A. (2006). Transformational leadership and job behaviors: The mediating role of core job characteristics. Academy of Management Journal, $49,327-340$.

Pierce, J. L., \& Gardner, D. G. (2004). Self-esteem within the work and organizational context: A review of the organization-based self-esteem literature. Journal of Management, 30, 591-622.

Pines, A. (1982). Helpers' motivation and the burn-out syndrome. In T. A. Wills (Ed.), Basic processes in helping relationships (pp. 453-475). New York: Academic Press.

Rosen, S., Mickler, S. E., \& Collins, J. E. (1987). Reactions of would-be helpers whose offer of help is spurned. Journal of Personality and Social Psychology, 53, 288-297

Ryan, R. M., \& Connell, J. P. (1989). Perceived locus of causality and internalization: Examining reasons for acting in two domains. Journal of Personality and Social Psychology, 57, 749-761.

Ryan, R. M., \& Deci, E. L. (2000). Self-determination theory and the facilitation of intrinsic motivation, social development, and well-being. American Psychologist, $55,68-78$.

Schaller, M., \& Cialdini, R. B. (1988). The economics of empathic helping: Support for a mood management motive. Journal of Experimental Social Psychology, 24, $163-181$.

Smith, K. D., Keating, J. P., \& Stotland, E. (1989). Altruism reconsidered: The effect of denying feedback on a victim's status to empathic witnesses. Journal of Personality and Social Psychology, 57, 641-650.

Swann, W. B. Jr., Polzer, J. T., Seyle, D., \& Ko, J. (2004). Finding value in diversity: Verification of personal and social self-views in diverse groups. Academy of Management Review, 29, 9-27.

Taris, T. W. (2006). Is there a relationship between burnout and objective job performance? A critical review of 16 studies. Work and Stress, 20, 316-334.

Tett, R. P., \& Guterman, H. A. (2000). Situation trait relevance, trait expression, and cross-situational consistency: Testing a principle of trait-activation. Journal of Research in Personality, 34, 397-423.

Vansteenkiste, M., Neyrinck, B., Niemiec, C. P., Soenens, B., De Witte, H., \& Van den Broeck, A. (2007). On the relations among work value orientations, psychological need satisfaction and job outcomes: A self-determination theory approach. Journal of Occupational and Organizational Psychology, 80, 251-277. 
Williamson, G. M., \& Clark, M. S. (1989). Providing help and desired relationship type as determinants of changes in moods and self-evaluations. Journal of Personality and Social Psychology, 56, 722-734.

Wills, T. A. (1978). Perceptions of clients by professional helpers. Psychological Bulletin, 85, 968-1000.
Wright, T. A., \& Cropanzano, R. (1998). Emotional exhaustion as a predictor of job performance and voluntary turnover. Journal of Applied Psychology, 83, 486-493.

Wrzesniewski, A., \& Dutton, J. E. (2001). Crafting a job: Revisioning employees as active crafters of their work. Academy of Management Review, 26, 179-201. 